\title{
IMPLANTAÇÃO DO PROGRAMA DE GERENCIAMENTO DE RESÍDUOS QUÍMICOS NOS LABORATÓRIOS DE QUÍMICA DA UTFPR-PG
}

\section{DEPLOYMENT OF THE WASTE MANAGEMENT OF CHEMICALS IN LABORATORIES OF CHEMISTRY UTFPR-PG}

\author{
Isis Mariane Fornazzari ${ }^{1}$, Júlio César Stiirmer ${ }^{2}$ \\ ${ }^{1,2}$ Universidade Tecnológica Federal do Paraná - UTFPR - Ponta Grossa - Brasil isisutf@yahoo.com.br
}

\begin{abstract}
Resumo
A implantação de um programa de gerenciamento de resíduos é algo que exige, antes de tudo, mudanças de atitudes, e por isso, é uma atividade que traz resultados a médio e longo prazo, além de requerer reeducação e uma persistência contínua. $O$ objetivo do projeto é a implantação do programa de gerenciamento de resíduos químicos nos laboratórios de Química da UTFPR-PG, através de procedimentos adequados para a segregação e descarte final dos resíduos químicos gerados nos respectivos laboratórios.
\end{abstract}

Palavras-chave: projeto, programa, gerenciamento, segregação.

\section{Introdução}

A adoção de estratégias tem um propósito relacionado à preservação ambiental, observadas atualmente nas mais elementares atividades humanas, e é resultante de uma evolução da conscientização dos cidadãos e empresas sobre os danos causados por uma atividade, quer seja em processos industriais, quer seja em instituições de ensino (IZZO, 2000).

Durante os últimos anos cresceu a nível mundial a conscientização por parte das indústrias químicas, das instituições acadêmicas e dos órgãos governamentais a respeito da necessidade de tratamento eficaz ou de uma adequada disposição final de qualquer tipo de resíduo (EMPTOZ, 1998).

A ausência de órgão fiscalizador, a falta de visão e o descarte inadequado levaram muitas Universidades a poluir o meio ambiente, promover o desperdício de material e arcar com o mau gerenciamento dos produtos sintetizados ou manipulados. Houve realmente um tempo onde os resíduos eram jogados na pia dos laboratórios sem preocupação sequer com a segurança do aluno. Dentro desse contexto, diversas Instituições Federais, Estaduais e Particulares no Brasil vêm buscando gerenciar e tratar seus resíduos de forma a diminuir o impacto causado ao meio ambiente, 
criando também um novo hábito a fazer parte da consciência profissional e do senso critico dos alunos, funcionários e professores (AFONSO et al, 2003).

O primeiro passo para enfrentar este desafio é assumir conscientemente a responsabilidade com os resíduos gerados nos laboratórios das universidades. As universidades como formadoras de mão de obras especializadas, precisa despertarem a atenção dos alunos de graduação e pósgraduação para esta questão e lhes fornecer as ferramentas básicas, que lhes permitam exercer suas atividades profissionais de forma "limpa" (GERBASE et al, 2005).

O objetivo do projeto é a implantação do programa de gerenciamento de resíduos químicos nos laboratórios de Química da UTFPR - Campus Ponta Grossa, através de procedimentos adequados para a segregação e descarte final dos resíduos químicos gerados.

\section{Metodologia}

A UTFPR (Universidade Tecnológica Federal do Paraná) Campus Ponta Grossa, consciente da necessidade de instruir o futuro profissional dos alunos acerca dos problemas relacionados ao meio ambiente, incluindo a questão da geração, tratamento e destino final dos resíduos químicos gerados nos Laboratórios de Químicas dos cursos de Tecnologia em Alimentos, Técnico em Agroindústria e Ensino Médio, vem tomando diversas medidas sobre este assunto desde setembro de 2007.

O programa de gerenciamento engloba os Laboratório de Química Orgânica, Química Geral, Química Analítica, Físico-Química, Bioquímica e Métodos Instrumentais.

A segregação dos resíduos deverá ser realizada levando em consideração as seguintes classes:

- Solventes Orgânicos halogenados: derivados de hidrocarbonetos que possuem átomos de elementos halogênicos (flúor, cloro, bromo, iodo), exemplo: derivados halogenados ou haletos orgânicos; clorofórmio; bromoformio; cloreto de etila; cloreto de benzila.

- Solventes Orgânicos não halogenados: Solventes orgânicos e soluções orgânicas que não contenham elementos de halogênios (cloro, flúor, bromo, iodo), exemplo: hidrocarbonetos: hexano, benzeno, tolueno; alcoóis: metano, etanol; ácidos carboxílicos; aldeídos; éteres; ésteres.

- Compostos Inorgânicos: são substâncias químicas que não contém na sua estrutura carbono, exemplo: ácidos, bases, sais e óxidos inorgânicos.

- Compostos Orgânicos: são substâncias químicas que contém na sua estrutura carbono e hidrogênio, e muitas vezes com oxigênio, nitrogênio, enxofre, fósforo e boro, exemplo: todos os compostos orgânicos de todas as funções. 
- Solução contendo metais pesados: metais pesados são altamente reativos e bioacumulativos, ou seja, o organismo não é capaz de eliminá-los, exemplo: soluções contendo: Chumbo, Bário, Cádmio, Arsênio, Selênio, Cromo, Mercúrio, Níquel, Zinco, Alumínio, Prata, Cobre.

- Outros compostos: são todos os resíduos que não se não se enquadraram dentro das classificações anteriores.

Esses resíduos serão armazenados em bombonas que se encontram presentes nos laboratórios, onde será segregado conforme as classificações. Cada laboratório possui seis bombonas de 20L destinadas ao armazenamento dos resíduos gerados. Essas bombonas possuem rótulos que as diferenciam entre si de acordo com a classificação dos resíduos.

Após o enchimento das bombonas presente nos laboratórios, os resíduos são depositados em bombonas de 100L. O armazenamento dos resíduos gerados nos laboratórios está sendo em um local provisório, onde ainda não possui todos os requisitos adequados de segurança.

A empresa responsável pela destinação final dos resíduos químicos tem que ser especializada no tratamento e destinação final dos resíduos químicos, tem de possuir soluções ambientais integradas no tratamento e destinação final de resíduos químicos, garantirem os mais altos padrões de qualidade, conferir credibilidade, segurança aos serviços prestados, competência e responsabilidade sócio-ambiental (ESSENCIS, 2008).

\section{Resultados}

Os resíduos foram separados e classificados de acordo com os pedidos dos professores participantes do projeto conforme os tipos de resíduos gerados nos respectivos laboratórios, devido à necessidade de dispor os resíduos adequadamente.

A rotulagem, a segregação dos resíduos nos laboratórios e a destinação final desses resíduos descritos no relatório foram feitos de acordo com as referências. Estes resíduos, gerados das aulas práticas, serão armazenados, e rotulados como passivos, em um local provisório, já escolhido dentro da instituição até a construção do abrigo definitivo.

Os resultados da implantação do programa de gerenciamento de resíduos químicos foram obtidos no final do primeiro semestre de 2008, e estão sendo mostrados conforme figura 1. 
Figura 1 - Resíduos gerados nos laboratórios da UTFPR Campus Ponta Grossa

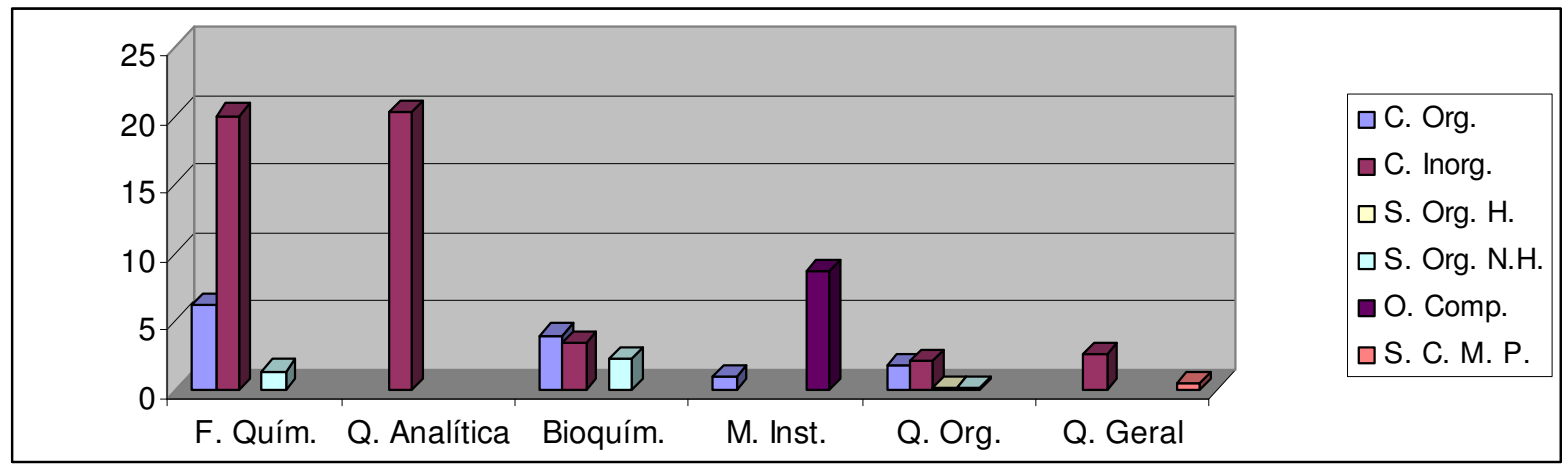

Fonte: resíduos gerados no primeiro semestre de 2008.

O laboratório de Físico-Química foi o maior gerador de resíduos químicos, sendo: o composto inorgânico, composto orgânico e solvente orgânico não halogenado. O resíduo composto inorgânico foi gerado em maior quantidade, com um volume de aproximadamente $20 \mathrm{~L}$. O menor resíduo gerado foi o solvente orgânico não halogenado tendo um volume de 1,4 L.

O laboratório de Química Analítica produziu apenas um tipo de resíduo. O resíduo químico, composto inorgânico, teve um volume de 20,3 L. O laboratório de Química Analítica foi o segundo maior gerador de resíduos químicos, mesmo gerando apenas um tipo de resíduo.

O laboratório de Bioquímica gerou em maior quantidade o composto orgânico, tendo um volume de 4L e o solvente orgânico não halogenado gerado em menor quantidade com um volume de $2,3 \mathrm{~L}$.

O laboratório de Métodos Instrumentais produziu dois tipos de resíduos químicos, o resíduo “outros compostos e compostos orgânicos". O maior resíduo gerado foi o resíduo, outros compostos, tendo um volume de 8L. Em menor quantidade foi gerado o resíduo, compostos orgânicos, tendo um volume de 1L. O laboratório de Métodos Instrumentais foi o único que gerou o resíduo "Outros Compostos".

O laboratório de Química Orgânica produziu os resíduos, compostos inorgânicos, compostos orgânicos, solventes orgânicos não halogenados e solventes orgânicos halogenados. O resíduo gerado em maior quantidade foi o composto inorgânico com um volume de 2,2L e em menor quantidade o resíduo, o solvente orgânico halogenado com um volume de 0,2L.

O laboratório de Química Geral produziu os resíduos químicos, compostos inorgânicos e soluções contendo metais pesados. Obtendo-se em maior quantidade o resíduo, composto inorgânico com um volume de 2,6L e em menor quantidade o resíduo, soluções contendo metais pesados, com um volume de $0,5 \mathrm{~L}$. Os outros resíduos não foram gerados no laboratório. O resíduo “soluções contendo metais pesados” foi gerado unicamente no laboratório de Química Geral.

Os laboratórios envolvidos no programa produziram no primeiro semestre de 2008 um volume total de 74,85L. Estes resíduos químicos gerados neste primeiro semestre possivelmente 
mudarão nos próximos anos, devido à criação de um novo curso de Engenharia de Produção Química.

\section{Discussão}

A implantação do programa de gerenciamento de resíduos químicos nos laboratórios de química da UTFPR-PG está em fase de implantação, sujeita a várias mudanças e melhorias. Essas melhorias se devem à construção do Abrigo de Resíduos Químicos Perigosos que está sendo construído e possivelmente esteja pronto até o final do segundo semestre de 2008. Esta construção será o abrigo definitivo onde irão ser armazenados os resíduos químicos. O abrigo de resíduos perigosos definitivo provavelmente esteja pronto até o final do semestre.

Até o momento, observa-se que os resultados que estão sendo apresentados são promissores, onde se observou que a implantação do programa de gerenciamento de resíduos químicos nos laboratórios foi satisfatória, tendo uma redução semestralmente de aproximadamente 75L ou mais, de resíduos químicos que não serão mais jogados nos rolos de pias, diminuindo assim a contaminação do meio ambiente. Também se obteve uma aceitação por parte dos professores envolvidos no projeto, e principalmente uma conscientização de toda a comunidade escolar.

\section{Abstract}

The establishment of a waste management program is something that requires, first of all, changes in attitudes, and therefore, is an activity that brings results in the medium and long term, in addition to rehabilitation and requires a continuous persistence. The project goal is to introduce the program management of chemical waste in the laboratories of Chemistry of UTFPR-PG, through appropriate procedures for the segregation and final disposal of chemical waste generated in their laboratories.

Key-words: project, program, management, segregation.

\section{Referências}

AFONSO, J. C.; NORONHA, L. A.; FELIPE, R. P.; FREIDINGER, N. Gerenciamento de resíduos laboratoriais: recuperação de elementos e preparo para descarte final. Química Nova. v. 26, n.4, p.602-611, 2003.

EMPTOZ, G. Chemical Ind. Europe. p.1850-1914. n. 293, 1998.

ESSENCIS SOLUÇÕES AMBIENTAIS INTEGRADAS. Disponível em: <http://www.essencis.com.br> Acesso em: 22-mar-2008.

GERBASE, A. E.; COELHO, F. S.; MACHADO, P. F. L.; FEREIRA, V. F. Gerenciamento de resíduos químicos em instituições de ensino e pesquisa. Química Nova. v. 27, n. 1, p.3, 2005.

IZZO, R. M. Waste minimization and pollutions prevention in university laboratories. Chemical Health \& Safety, p.2933, may/june, 2000 . 